\title{
Adult Students' Perceptions in Distance Education Learning Environments Based on a Videoconferencing Platform - QoE Analysis
}

\author{
Toni Malinovski, Tatjana Vasileva-Stojanovska \\ Faculty of Computer Science and Engineering, Ss. Cyril and \\ Methodius University, Skopje, Republic of Macedonia \\ tmalin@nbrm.mk tatjanav@nbrm.mk
}

\author{
Dobri Jovevski \\ Primary School Ilinden, Kriva Palanka, Republic of Macedonia \\ dobri.jovevski@gmail.com
}

\author{
Marina Vasileva and Vladimir Trajkovik \\ Faculty of Computer Science and Engineering, Ss. Cyril and \\ Methodius University, Skopje, Republic of Macedonia \\ vasileva marina@yahoo.com trvlado@finki.ukim.mk
}

\begin{abstract}
Material published as part of this publication, either on-line or in print, is copyrighted by the Informing Science Institute. Permission to make digital or paper copy of part or all of these works for personal or classroom use is granted without fee provided that the copies are not made or distributed for profit or commercial advantage AND that copies 1) bear this notice in full and 2) give the full citation on the first page. It is permissible to abstract these works so long as credit is given. To copy in all other cases or to republish or to post on a server or to redistribute to lists requires specific permission and payment of a fee. Contact Publisher@InformingScience.org to request redistribution permission.
\end{abstract}

Distance education learning environments provide tremendous convenience and flexibility, allowing busy, mobile adult learners to engage in education while coping with their limited resources in terms of time, energy and finances. Following a student-centered approach this study investigates adult students' subjective perceptions while using distance education systems based on a videoconferencing platform as Quality of Experience (QoE). Based on a literature review, sociological behavior and expectations, we have constructed a structural equation model (SEM) illustrating relations among different variables that can predict positive levels of adult students' QoE, thus providing guidelines for proper development. We have tested the model using a survey of 198 primary education school teachers involved in a videoconferencing-based learning program for teacher enhancement. Results show a good fit to the model developed. The analysis showed that adult students' QoE is directly influenced by appropriateness of teacher-student interaction and ease of participation, as well predicted by students' motivation to attend similar trainings. Additionally, we found that variances in technical quality did not directly influence their QoE from the learning sessions.

Keywords: Quality of Experience, adult students, distance education, lifelong learning, videoconferencing, structural equation modeling. 


\section{Introduction}

Continuous education is important to individuals, institutions and society as a whole, especially due to the accelerated changes in modern living in the past few decades. When we refer to education, we mostly think about children and the young population, instructed by adults. But the adult population is also interested in the pursuit of knowledge for either personal or professional reasons. Adults, as non-traditional students, are engaging in different activities to continue their education through various forms of learning that provide them with adequate knowledge in a specific area of study. Some of these forms include self-learning, attendance at lectures, training, conferences, workshops, etc. Terminology related to adult education has changed over time, indicating a shift in educational perspectives and teaching practices. 'Continuing education', as used in the literature, consists of all learning activities, formal and informal, by which individuals seek to upgrade their knowledge, attitude and competencies (Jarvis, 1995; Smith, 2005; Stone, 1986). Currently accepted terminology referred to as 'lifelong learning' indicates a change from education to learning and incorporates learning from every aspect of our lives - social relationships, environment, society and culture (Field, 2006; Tight, 2002). There are differences between adults and other types of students, since adults have more life experience and have already gone through the process of standard education. They are usually motivated by the latest trends promoted by society, their wish to advance in their profession, re-career, satisfy job requirements, or acquire new skills and knowledge for personal reasons, which are all built on their past learning experience and practice (Knowles, Holton, \& Swanson, 1998). On the other hand, as life becomes more complex, different education forms and models have to be developed for better integration of the educational process in modern society. During the last decade, the pace of technological change has increased so quickly that it has significantly affected every area of modern living. Recent technological developments have introduced world-wide collaboration, social networking, virtualization of resources and participants, videoconferencing, on-line/off-line e-learning, etc. into the learning process (Brady, Holcomb, \& Smith, 2010; Garrison, 2011; Lawson, Comber, Gage, \& Cullum-Hanshaw, 2010; Longworth, 2013). Distance education has created new opportunities for information and knowledge transfer, separating the teacher, as a source of information, and the students through time and space.

Adult students have to find a proper balance between growing demands at work and in their personal life. Their learning activities have to compete with limited resources that adults generally possess in terms of time, energy and finances (Eastmond, 1998; Giancola, Grawitch, \& Borchert, 2009). The distance education methodologies and solutions can successfully meet these demands and promote wider adaptation of e-learning in adult population. Having in mind that adult learning process builds on previously acquired knowledge, skills and attitude of individuals (Stone, 1986), the success of adult distance learning practices is closely dependent on adults students' beliefs, satisfaction and expectations from the delivery methods (Donavant, 2009). Hrastinski (2008) has investigated the importance of the communication media (asynchronous and synchronous) as key in transforming the focus on e-learners as individuals to e-learners as social participants during lifelong learning. Levenberg and Caspi (2010) have explored elementary school teachers' perceptions of learning in formal/informal online and face-to-face learning environments and found that the medium makes a difference in perceived learning in informal environments, but not in formal ones. In like manner, different researchers have focused on learning technologies for adult education and the success of the learning process (Eastmond, 1998, LeNoue, Hall, \& Eighmy, 2011; Mason, 2006). Still, due to the different nature of adult students, additional research is required that follows a student-centered approach (Hannafin, Hill, Land, \& Lee, 2014; Knowles et al., 1998; Weimer, 2013), especially focusing on adult students' satisfaction and quality expectations from the distance learning environments. Hence, better understanding of students' experiences is vitally important to the educational process and the learning experience itself plays an important role in learning outcomes. 


\section{Purpose of the Study}

This study is one of few attempts to investigate adult students' subjective expectations while using interactive distance learning systems (based on videoconferencing technologies) in terms of Quality of Experience (QoE). In the last few years, QoE ("Quality of Experience", 2011) has emerged as a fully user-oriented approach which focuses on the social element, users' subjective expectation and evaluation of systems' delivery and performance (Kalliris, Dimoulas, Veglis, \& Matsiola, 2011; Kist \& Brodie, 2012; W. Wu et al., 2009; Zhang, Xu, \& Cheng, 2011). Furthermore, videoconferencing-based educational systems provide tremendous convenience and flexibility for adult students, while bridging the distance between the teacher as a source of information and the students. Such interactive learning activities can meet the demands of adult students since they closely resemble face-to-face educational environments and can make students feel like participants rather than isolates (Lawson et al., 2010; Murphy, Rodríguez-Manzanares, \& Barbour, 2011). Therefore, the purpose of this study is to provide empirical research on videoconferencing-based learning environments for adult population, while predicting or explaining the determinants that influence students' positive experiences during the learning process. Through a literature review on adult education and existing models for technology acceptance, we propose a model which takes into account complex correlations among different factors that influence students' positive QoE and ideally describes technology independent guidelines. With this quantitative QoE analysis, we can help readers understand the nature of adult students while using videoconferencing for lifelong learning, promote improvement of practice and provide valuable information to all stakeholders of distance education institutions during evaluation of their educational systems. This study systemically analyzes a wide array of factors that can predict higher levels of students' QoE that inevitably determine perceived learning environments that encourage deeper approaches, structured to improve the quality of student learning (Trigwell \& Prosser, 1991).

\section{Literature Review}

In an attempt to differentiate 'the art and science of teaching adults' as opposed to 'the art and science of teaching children', Knowles (1980) has developed a theory of 'andragogy' for any form of adult learning in contrast to 'pedagogy'. The andragogical model, as conceived by Knowles, was premised on four crucial assumptions of adult learning: (1) self-concept in which adults move from dependency to self-directedness; (2) experience which guides adults in their learning activities; (3) readiness to learn as internal motivation to attend subjects that have immediate relevance to their job or personal life; and (4) orientation to learning which indicates a shift from content-oriented towards problem-centered learning. Additionally, motivation to learn was added later as fifth assumption, since he had recognized that adults respond better to internal versus external motivators. In like manner, another influential theory on adult education, referred as 'experiential learning' (Kolb, 1984), stressed the necessity to approach adults differently than young students due to the central role that experience plays in the learning process.

Over the years, the Internet has emerged as the latest vehicle through which institutions can deliver credit and noncredit distance education courses, while allowing a variety of asynchronous (two-way communication involving time delay between transmission and receipt) and synchronous (interactive communication) activities (Bower \& Hardy, 2004; Bouhnik \& Carmi, 2012; Murphy et al., 2011; Somenarain, Akkaraju, \& Gharbaran, 2010; Yamagata-Lynch, 2014). In his theory of transactional distance, Moore (1997) hypothesized that, in the hands of progressive teachers, teleconferencing gives opportunity not only to reduce distance but also to increase autonomy of learners. Other researchers have also identified videoconferencing as a new dimension of interaction and communication that was previously unavailable in online learning environment (Gill, Parker, \& Richardson, 2005; Lawson et al., 2010; Taylor, 2009; Y. Wang \& Chen, 2007). 
Adult distance education possibilities do not differ from the ones available to young population. Still, differences may arise as result of different motivating factors, preferences, strategies towards learning, already accumulated information and life experience, which adults tend to transfer into their learning situations (Eyitayo, 2013; Knowles et al., 1998; Merriam \& Caffarella, 1991; Richardson, 2013). Therefore it is important to understand adult students and their subjective experience from the learning environment. According to Moore and Kearsley (1996), "most distance education students are adults between the ages of 25 and 50. Consequently, the more one understands the nature of adult learning, the better one can understand the nature of distance learning" (p. 153). To some extent, Knowles (1980) used his assumptions and proposed a program-planning model for designing, implementing and evaluating education experience with adults. Based on adult learning theories, Cercone (2008) examined the characteristics of adult learners and provided an analysis of how these characteristics influence the design of an online learning environment. According to Fidishun (2000), factors that motivate adults, for example increased self-esteem, job satisfaction, quality of life, etc., can be built into online environments through different educational methods. But still, empirical research that provides guidelines for educational development while predicting adult students' behavior and overall experience from different distance learning environments is almost nonexistent.

On the other hand, researchers have explored the social aspect and used the theory of reasoned actions (TRA) (Ajzen \& Fishbein, 1980) to provide information for users' acceptance of modern technologies. Based on this theory, they have addressed factors influencing perceived ease of use and usefulness of technology, users' attitude toward using and intention to use technology, while applying the technology acceptance model (TAM) (Davis, Bagozzi, \& Warshaw, 1989) or extended TAM to the use of different technological solutions (Liu, Chen, Sun, Wible, \& Kuo, 2010; Ng, Shroff, \& Lim, 2013; Saadé, Nebebe, \& Tan, 2007; Sahin, \& Shelley, 2008; X. Wu \& Gao, 2011). Having in mind the lack of literature that explores adult students' behavior, if we approach adult students the same as any distance education practitioner and reuse the variables of technology acceptance models aligned with adult learning theories, we can provide results that explain their nature and subjective experience. In the same context, different studies have already demonstrated QoE as a more holistic evaluation than mere narrowly focused end-user experience (Kalliris et al. 2011; Molnar, Hava-Muntean, \& Cristea, 2009; W. Wu et al., 2009; Zhang et al., 2011). Gong, Yang, Huang and Su (2009) have defined a QoE model that focused on the relationship between the technical and QoE parameters that consisted of five factors: availability, usability, integrality, retainability and instantaneousness. Malinovski, Lazarova and Trajkovik (2012) have focused on the social aspect regarding learner-content interaction in distance learning activities and proposed a model where easy usage and adaptability of the system predict students' experience while using online learning portals. Still, despite these isolated efforts to define QoE models, many issues regarding identification of influencing factors in distance learning environments remain unanswered and require significantly more research.

\section{Research Model and Hypotheses}

There are different factors that influence the success of a videoconferencing-based educational system, like ease of use, quality and synchronization of video/audio signals, integration with collaboration tools, proper teaching approach, student subjective experience, etc. In the case of adult students, some factor may be more influential than others, since they are inclined towards a practical and reflexive approach to knowledge (Knowles, 1980), while the age span could lead to different attitudes towards new technologies and motivation for their use in practice (Milheim, 2007; Selwyn, Gorard, \& Furlong, 2005). In this study, we have incorporated the advances made via the technology acceptance models, have moved beyond mere acceptance, and tried to evaluate similar and different variables that can influence a higher level of adult students' positive QoE. Since distance education and technology are closely connected, we have adopted 'ease of use' and 'atti- 
tude' of TAM and combined them with adult students' motivators (intrinsic and extrinsic) influenced by the assumptions related to motivation in adult learning theories (Fidishun, 2000; Knowles, 1980; Merriam \& Caffarella, 1991). The technical performance of distance educational systems, especially the interactive ones, depends on infrastructure level (transport infrastructure, network-based Quality of Service (QoS), etc.) and application level (web-content, conferencing services, application-based QoS, etc.). Since our approach is student-centered, we have also included a technical performance variable, but constructed as students' perception of the performance and delivered services. Having in mind that during sociological and behavioral research multi-item measures are more adequate than single-item measures (Nunnally, 1978), each of the explored key factors that affect adults students' QoE was formulated as latent constructs, measured via several observed variables. In like manner, we have formulated QoE as adult students' perceived experience for natural feeling, increased efficiency and productivity, and overall satisfaction from the learning process. Thus, we have defined nineteen (19) observed variables that represent relevant indicators underlying the domain of each construct (Table 1).

Table 1: Latent constructs and their observed variables (indicators)

\begin{tabular}{|c|c|c|}
\hline CONSTRUCT & INDICATOR & DESCRIPTION \\
\hline \multirow[t]{4}{*}{ EASY } & Easy1 & Students' think it was easy to follow the lesson through VC \\
\hline & Easy 2 & Appropriateness and simplicity of teacher-student interaction \\
\hline & Easy3 & $\begin{array}{l}\text { The degree to which students were able to easily understand the } \\
\text { content }\end{array}$ \\
\hline & Easy4 & $\begin{array}{l}\text { The degree to which the technological solution fitted learning } \\
\text { requirements }\end{array}$ \\
\hline \multirow[t]{3}{*}{ ATTITUDE } & Att1 & Acceptance of VC during the lessons \\
\hline & Att2 & $\begin{array}{l}\text { Beliefs regarding possibility to bridge the distance between the } \\
\text { teacher and the students }\end{array}$ \\
\hline & Att3 & $\begin{array}{l}\text { Attitude towards new interactive technological solutions for } \\
\text { learning }\end{array}$ \\
\hline \multirow[t]{4}{*}{ MOTIVATION } & Motiv1 & Level of motivation to attend $\mathrm{VC}$ based classes in the future \\
\hline & Motiv2 & $\begin{array}{l}\text { Beliefs to recommend and motivate others to attend similar } \\
\text { classes }\end{array}$ \\
\hline & Motiv3 & Level of motivation for attendance to satisfy job requirements \\
\hline & Motiv4 & Level of motivation to use the recorded VC session for learning \\
\hline \multirow[t]{4}{*}{ TECHNICAL } & Tech1 & Students' perceived quality of the video signal \\
\hline & Tech2 & Students' perceived quality of the audio signal \\
\hline & Tech3 & Beliefs regarding proper audio/video synchronization \\
\hline & Tech4 & $\begin{array}{l}\text { Students' perceived level of proper functioning of the equip- } \\
\text { ment }\end{array}$ \\
\hline \multirow[t]{4}{*}{ QoE } & QoE1 & $\begin{array}{l}\text { Perceived experience for the comfort during learning and in- } \\
\text { creased efficiency }\end{array}$ \\
\hline & QoE2 & $\begin{array}{l}\text { Perceived experience for increased possibilities for learning and } \\
\text { productivity }\end{array}$ \\
\hline & QoE3 & $\begin{array}{l}\text { The degree to which students think this type of learning is inter- } \\
\text { esting and enjoyable }\end{array}$ \\
\hline & QoE4 & Overall experience during distance learning enhanced with VC \\
\hline
\end{tabular}

Note. $\mathrm{VC}=$ videoconferencing 
The presented observed variables were further used in a reflective measurement where a change in a latent construct variable must precede a variation in the indicator, thus providing a measure for the construct (Churchill, 1979). Furthermore, the selected latent constructs provide sufficient information for a reliable QoE analysis, model development and testing of hypotheses regarding adult students' perceptions in distance educational systems based on a videoconferencing platform.

This research focuses on the cognitive level while abstracting the actual technical setup and utilized tool for videoconferencing. Still, following a student-centered approach, it researches the technical behavior and proper functioning of the equipment as a perceived experience by the involved adult students.

Therefore we have formulated the following hypotheses that describe the possible connections between the research constructs, organized in a manner that can be further illustrated as a research model:

Hypothesis 1: Students' perceived technical quality and proper functioning of the system influence students' ease of participating in the learning sessions and understanding of the content (Hla); and influence students' acceptance of videoconferencing and interactive technologies for learning $(H 1 b)$;

Hypothesis 2: Students' perceived technical quality and proper functioning of the system influence positive level of students' QoE for increased efficiency, productivity and successful distance learning process.

Consistent with prior studies (Lee, Cheung, \& Chen, 2005; Liu et al., 2010, X. Wu \& Gao, 2011), we believe that relationships among the latent construct, which reflect on ease of use, motivation and adult students' acceptance of interactive technologies, can demonstrate significant strengths. Hence, we have formulated the following hypotheses:

Hypothesis 3: Ease of participation and learning, appropriate teacher-student interaction influence students' acceptance of videoconferencing $(\mathrm{H} 3 \mathrm{a})$; as well influence students' motivation (intrinsic and extrinsic) to participate in videoconferencing classes, to use the recorded sessions for learning and recommend similar classes to other $(H 3 b)$;

Hypothesis 4: Adult students' motivation to use videoconferencing based systems influence their attitude towards these interactive technologies.

The presented hypotheses formulate the relationships between research constructs as determinants that altogether influence a higher level of students' experience. Since QoE is the desired outcome variable, we have reviewed the nature of each construct and referred indicators and formulated the following hypothesis:

Hypothesis 5: Adult students' QoE, while participating in distance learning environments based on videoconferencing platforms, is directly influenced by the appropriateness of teacher-student interaction and ease of participation ( $\mathrm{H} 5 \mathrm{a}$ ) ; is influenced by students' attitude towards videoconferencing technologies and acceptance of the new learning methodology $(H 5 b)$; and is also predicted by students' motivational factors (intrinsic and extrinsic) to attend videoconferencing clas$\operatorname{ses}(H 5 c)$.

Based on the above proposed hypotheses and theoretical variables, we have developed our research model that explains the natures of adult students and illustrated relationships between all factors that influence adults students' QoE in distance education learning environments based on a videoconferencing platform. Figure 1 illustrates the proposed model with hypotheses and complex relationships between the researched latent variables. 


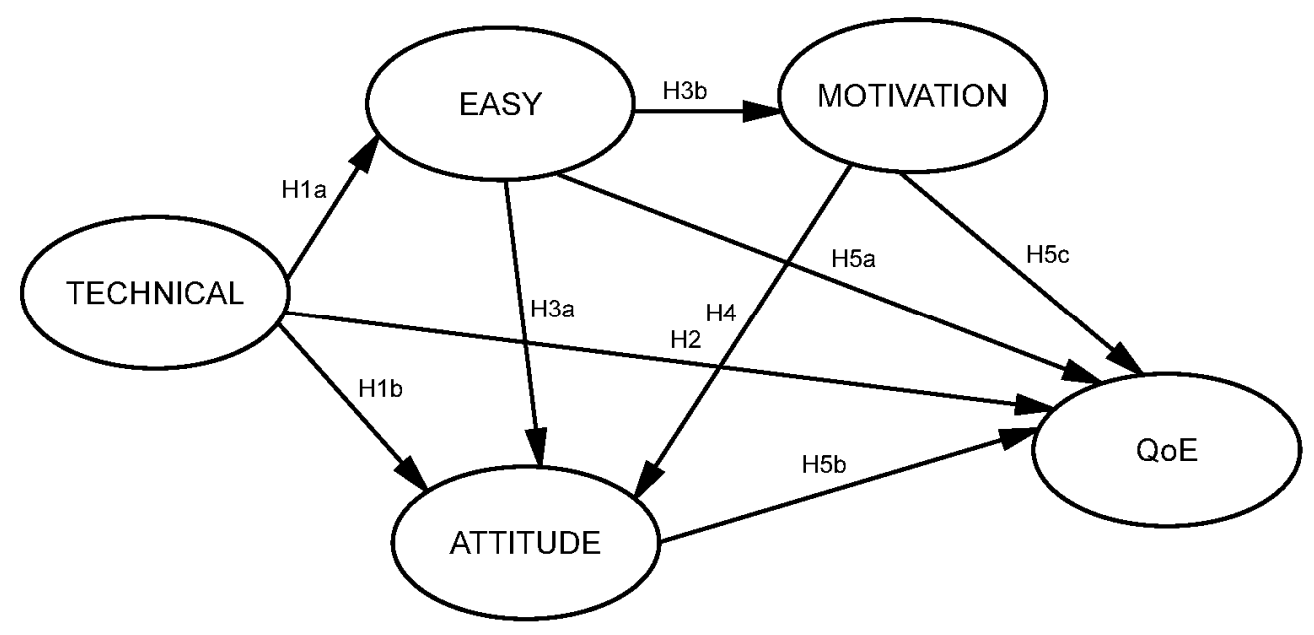

\section{Figure 1: Hypothesized model illustrating adult students' perceptions in distance} learning environments based on a videoconferencing platform.

The proposed model has one exogenous variable (TECHNICAL), since we have assumed that it is influenced by factors outside of this model that are coming from the application and networking level. This variable is acting as a predictor for EASY, ATTITUDE and QoE (endogenous variables). According to the researched hypotheses, this model also illustrates a causal relationship for the outcome of the remaining latent variables: EASY, ATTITUDE, MOTIVATION and QoE. Therefore, it focuses on factors influencing adult students' QoE in distance learning environments based on a videoconferencing platform, which is subjective opinion and would be difficult to quantify and measure otherwise.

\section{Methodology}

Interactive distance educational systems, especially ones based on videoconferencing platforms, are designed to bridge the distance between the teacher as a source of information and the student. There are different systems and tools that offer this type of education, but the success of the learning process is closely dependent on students' subjective experience, influenced by different factors. Having in mind the different nature of adult students, we have proposed a research model and discussed casual relationships between the identified factors that influence adult students' QoE in similar environments.

\section{Participants}

To test the model of this study, we have researched a distance education program that provides continuing education for primary school teachers in Macedonia. Thus, we involved teachers who were part of a learning program for the professional development of government officials and educators towards new approaches to teaching with the use of technology. Hence, we were able to work with a representative group of adult students who covered wide age span, live in large cities or villages, have different technological backgrounds and have been participating in distance education for some period. The involved participants chose to participate in this distance education program since they were intrinsically motivated to increase their professional competencies and upgrade their knowledge to satisfy the latest trends in primary education for better use of technology (as extrinsic motivators). The collected demographical information from the in- 
volved 198 participants indicated $43.88 \%$ female and $56.12 \%$ male in the adult student population, $34.34 \%$ of age $25-34$ years, $39.39 \%$ of age $35-44$ years, $23.23 \%$ of age $45-54$ years and $3.04 \%$ of age 55-64 years, reflecting the typical population of adult students interested in continuing education. $74.24 \%$ of these students live in smaller and bigger cities, while $25.76 \%$ live in different villages, thus representing urban and rural environments. During the evaluation period, $58.59 \%$ had already participated in similar distance educational courses (most of the students attended several learning sessions), while $41.41 \%$ had taken such a course for the first time.

\section{Design}

This educational program covered more than twenty learning sessions, taught by ten different teachers, with 6-12 participants in each session. The program provided different courses designed to offer students an integrated learning experience in which they could enhance their knowledge regarding the latest educational trends and participate in collaborative activities. In each learning session, the teacher was placed at one site and was linked over the internet to a group of students in different locations (small classrooms) or individual students participating from their home. Each site had a proper teacher/student camera and sound system, a display with a live picture of the teacher and/or a student participating in a conversation and an interconnecting device to the videoconferencing platform. The students participating from their home connected with a web browser over the internet while using their own computers equipped with a camera and speakers.

After each learning session, the teacher provided a link to an online questionnaire for student feedback regarding each particular course. These surveys contained necessary demographic question, control information, as well questions regarding the proposed measurements in this study. They were able to grade the observed indicators on each question on a scale from 1 to 6 , where 1 is strongly disagree and 6 is strongly agree.

\section{Data Analysis}

Structural equation modeling (SEM) is a multi-equation technique and a powerful way of testing the credibility of models (Bollen, 1989; Byrne, 2001) that include multiple dependent and independent variables, and inclusion of measurement errors in the analysis. Due to the sociological and behavioral nature of our research, we have used SEM to test the hypothesized model while using the data set from students' responses to see if the proposed theory matches the research data. Having in mind that SEM can be an iterative process, the initial model can be refined and revised if such changes are justified theoretically (J. Wang \& Staver, 2001). Therefore, during this QoE analysis, we have explored minor corrections and alternative models so the research data could adequately fit an ultimate model aligned with the research purpose and sound theories.

\section{Research Findings}

\section{Descriptive Statistics}

The adult distance education program that was researched in this study lasted approximately one year. During this period, we got a satisfactory $85 \%$ usable survey response rate ( $\mathrm{n}=198$ responses) from the involved adult students and stored the dataset in a central database for further research and analysis.

Before we could submit the research dataset for factor analyses, proper univariate statistical analysis was conducted to examine the nature of the gathered data. This examination included measures for mean score, standard deviation, skewness, and kurtosis of the observed variables that provided initial results and reliability of indicators, since any value outside the acceptable range could produce inaccurate calculations. 
Table 2 lists descriptive statistics of the observed variables with the necessary measurements.

\begin{tabular}{|c|c|c|c|c|c|}
\hline INDICATOR & MIN/MAX & MEAN & STD. DEVIATION & SKEW & KURTOSIS \\
\hline Easy 1 & $4 / 6$ & 5.49 & 0.703 & -1.025 & -0.278 \\
\hline Easy2 & $4 / 6$ & 5.48 & 0.658 & -0.895 & -0.315 \\
\hline Easy3 & $4 / 6$ & 5.35 & 0.723 & -0.638 & -0.851 \\
\hline Easy4 & $4 / 6$ & 5.25 & 0.681 & -0.364 & -0.836 \\
\hline Att1 & $4 / 6$ & 5.61 & 0.520 & -0.763 & -0.711 \\
\hline Att2 & $3 / 6$ & 5.42 & 0.755 & -1.082 & 0.352 \\
\hline Att3 & $4 / 6$ & 5.64 & 0.569 & -1.303 & 0.731 \\
\hline Motiv1 & $4 / 6$ & 5.79 & 0.465 & -2.191 & 4.171 \\
\hline Motiv2 & $4 / 6$ & 5.74 & 0.495 & -1.701 & 2.054 \\
\hline Motiv3 & $4 / 6$ & 5.57 & 0.572 & -0.960 & -0.068 \\
\hline Motiv4 & $4 / 6$ & 5.67 & 0.524 & -1.239 & 0.529 \\
\hline Tech1 & $4 / 6$ & 5.22 & 0.748 & -0.388 & -1.124 \\
\hline Tech2 & $2 / 6$ & 5.16 & 0.845 & -0.926 & 1.156 \\
\hline Tech3 & $3 / 6$ & 5.16 & 0.809 & -0.653 & -0.242 \\
\hline Tech4 & $4 / 6$ & 5.24 & 0.719 & -0.389 & 0.996 \\
\hline QoE1 & $5 / 6$ & 5.63 & 0.484 & -0.549 & -1.717 \\
\hline QoE2 & $4 / 6$ & 5.64 & 0.521 & -1.023 & -0.080 \\
\hline QoE3 & $4 / 6$ & 5.53 & 0.539 & -0.514 & -0.947 \\
\hline QoE4 & $4 / 6$ & 5.67 & 0.494 & -0.966 & -0.461 \\
\hline
\end{tabular}

As shown in Table 2, the descriptive results demonstrate the lowest mean scores on all technical indicators, while the measurements for motivation and QoE report the highest mean scores. All results have low standard deviations, which confirms that these responses were constructive in nature. From a statistical point of view, to evaluate the normality of the survey's data, we need to look at the absolute values for skewness (skew $>3.0$ indicates an extremely skewed value) and kurtosis (kurtosis $>8.0$ indicates a problem). These parameters were also satisfactory, which ensures that the survey's data is relevant (Curran, West, \& Finch, 1996) and can be used for further analyses.

\section{Reliability of the Constructs}

The reliability and internal consistency of the construct was examined using a Cronbach's alpha test, which is widely accepted to indicate the degree to which a set of indicators measure a single latent construct (Table 3). As a rule of thumb, alpha values for constructs higher than 0.70 represent good internal consistency (Nunnally, 1978), having in mind that high values do not mean that the scale is unidimensional. 
Table 3: Reliability results for the latent constructs $(n=198)$

\begin{tabular}{|l|c|c|}
\hline \multicolumn{1}{|c|}{ CONSTRUCT } & NO. OF ITEMS & CRONBACH'S ALPHA \\
\hline EASY & 4 & 0.892 \\
\hline ATTITUDE & 3 & 0.712 \\
\hline MOTIVATION & 4 & 0.888 \\
\hline TECHNICAL & 4 & 0.952 \\
\hline QoE & 4 & 0.823 \\
\hline
\end{tabular}

As shown in Table 3, the results show that the reliability for all constructs highly exceeds the alpha threshold level of 0.70, except for ATTITUDE which is close to the border level. Even though this is still satisfactory for surveys, it indicated that this construct could be further revised, if necessary, to improve the proposed model.

\section{Measurement Model}

Before the structural model is developed, which will test the proposed hypotheses and model fit against the dataset gathered from students' responses, a measurement model is needed which relates measured (observed) variables to latent constructs. This model will provide factor loadings between the latent variables and proposed observed indicators, with included errors of measurement. The standardized factor loadings estimates should be 0.5 or higher, and ideally 0.7 or higher (Nunnally, 1978). Figure 2 illustrates the measurement model according to the research data, tested for factors loading and reliability of measures.

As shown in Figure 2, results from the measurement model show that all factor loadings on indicators and their respective constructs are above the ideal value 0.70, with the exception for Att2 which loads with 0.57 . This model gives us preliminary information about possible factors that could influence adult students' QoE as well as presenting correlation values among construct that indicate relevant relationships between them. Furthermore, we assessed the measurement model for convergent validity and looked into two additional measures: average variance extracted (AVE) and composite reliability (CR) for each construct, which were derived from the factor loadings. A good rule of thumb suggest an AVE of 0.50 or higher indicating adequate convergent validity (values less than 0.50 indicates that on average, there is more error remaining in the items than there is variance explained by latent structure), while CR should be at least 0.70 (values between 0.60 and 0.70 may be acceptable provided that other indicators of a model's construct validity are good). Guided by the results for factor loadings in the measurement model and the Cronbach's alpha test for each constructs (data presented in Table 3), we have chosen to test if exclusion of Att 2 from the proposed model could provide better results and revise the initial model.

In addition, we have further inspected the measurement model for satisfactory values for standardized residual covariances and modification indices. We have noticed that Easy4 and e4 have the highest value for modification indices with some of the other factors (Hair, Anderson, Tatham, \& Black, 1998) and thus considered to also remove Easy4 for better model fit results. Table 4 reports CR and AVE values for each construct within the initial model (with Att2 and Easy4) and revised model (without Att2 and Easy4). 


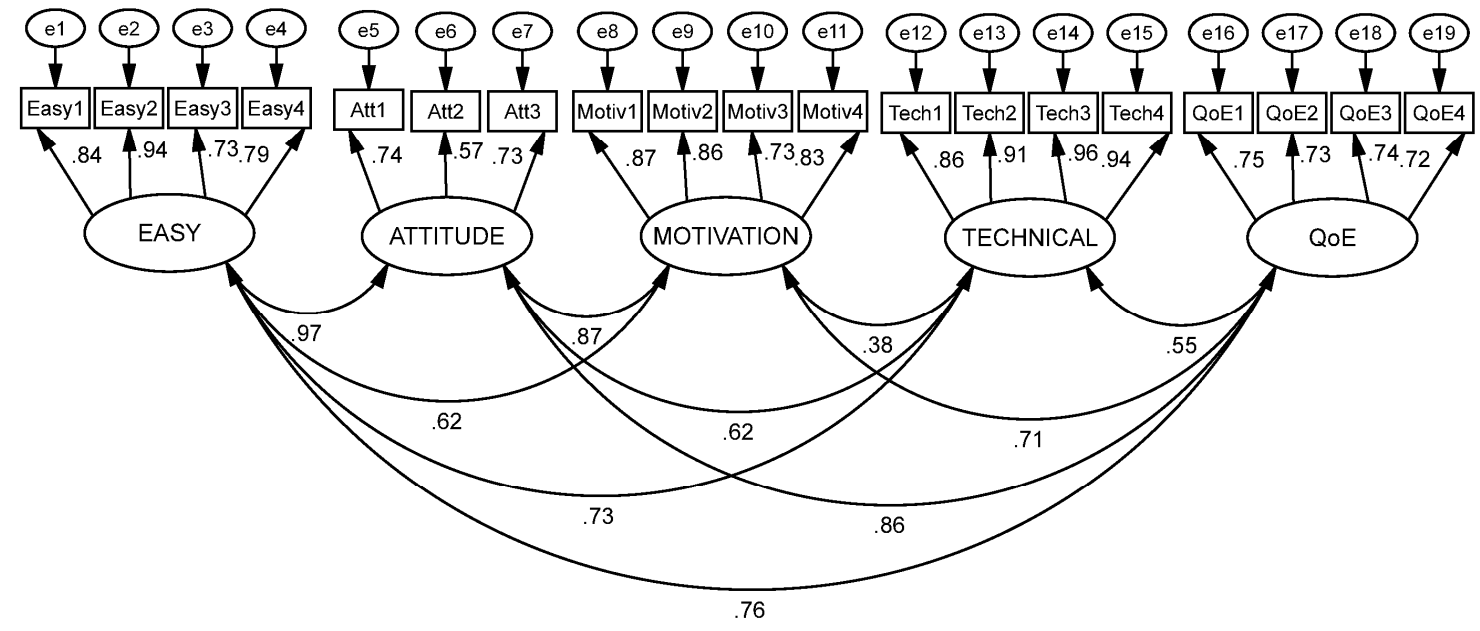

Figure 2: Measurement model.

The results in Table 4 show that the refinement of the referred constructs produced better results for convergent validity, especially since AVE of the ATTITUDE construct had increased above 0.50 and the CR value was closer to 0.70 . Thus we concluded that the revised measurement model reported adequate factor loading and convergent validity. During SEM, the validity of the measurement model proved the design, proposed methodology and measurement instruments. Further QoE analysis, through the development of a structural model, could illustrate how the latent variables (constructs) influence each other, especially students' QoE as a desired outcome.

Table 4: AVE and CR of each construct for the initial and revised measurement model

\begin{tabular}{|l|c|c|c|c|}
\hline \multicolumn{1}{|c|}{ CONSTRUCT } & $\begin{array}{c}\text { CR - INITIAL } \\
\text { MODEL }\end{array}$ & $\begin{array}{c}\text { CR - REVISED } \\
\text { MODEL }\end{array}$ & $\begin{array}{c}\text { AVE - INITIAL } \\
\text { MODEL }\end{array}$ & $\begin{array}{c}\text { AVE - REVISED } \\
\text { MODEL }\end{array}$ \\
\hline EASY & 0.876 & 0.896 & 0.689 & 0.714 \\
\hline ATTITUDE & 0.624 & 0.678 & 0.471 & 0.508 \\
\hline MOTIVATION & 0.870 & 0.871 & 0.681 & 0.682 \\
\hline TECHNICAL & 0.971 & 0.971 & 0.841 & 0.841 \\
\hline QoE & 0.716 & 0.716 & 0.538 & 0.538 \\
\hline
\end{tabular}

\section{Structural Equation Model}

The main purpose of this study is to distinguish proper determinants that correlate with each other and can predict students' QoE during an interactive videoconferencing learning session, with the focus on an adult population. Following our research methodology, we created a hypothesized model illustrating relevant observed and unobserved variables. Through a dataset gathered from the evaluation of students' perceptions of a targeted research adult group, this model was tested and refined through the measurement model, which is important in every social research since each study can be missing information and have hidden variables.

A structural equation model addresses the complex relationships among underlying constructs and attempts to account for these confounding variables while including measurement errors into the model. During the development of this model, we followed the hypothesized model (Figure 1), but also examined the possible model fitted to the dataset gathered from adult students' re- 
sponses. During examination of the results, we noticed that the hypothesized path between TECHNICAL and QoE (the path that also demonstrated a low correlation value within the measurement model) reported $\mathrm{p}>0.05$ and diminished the required values for model fit. Therefore it led us to the conclusion that the proposed Hypothesis 2 is not supported. Hence, we decided once again to refine the model and drop the path between these constructs towards an ultimate model. The rejection of Hypothesis 2 is logical since adult students' QoE during distance education may not be directly influenced by the technical behavior and systems parameters when they operate within acceptable levels.

Having in mind the structure of the hypothesized model, the refinement made during the measurement model analysis and initial model fit parameters, the ultimate model (revised structural model) proposed in this study is shown in Figure 3.

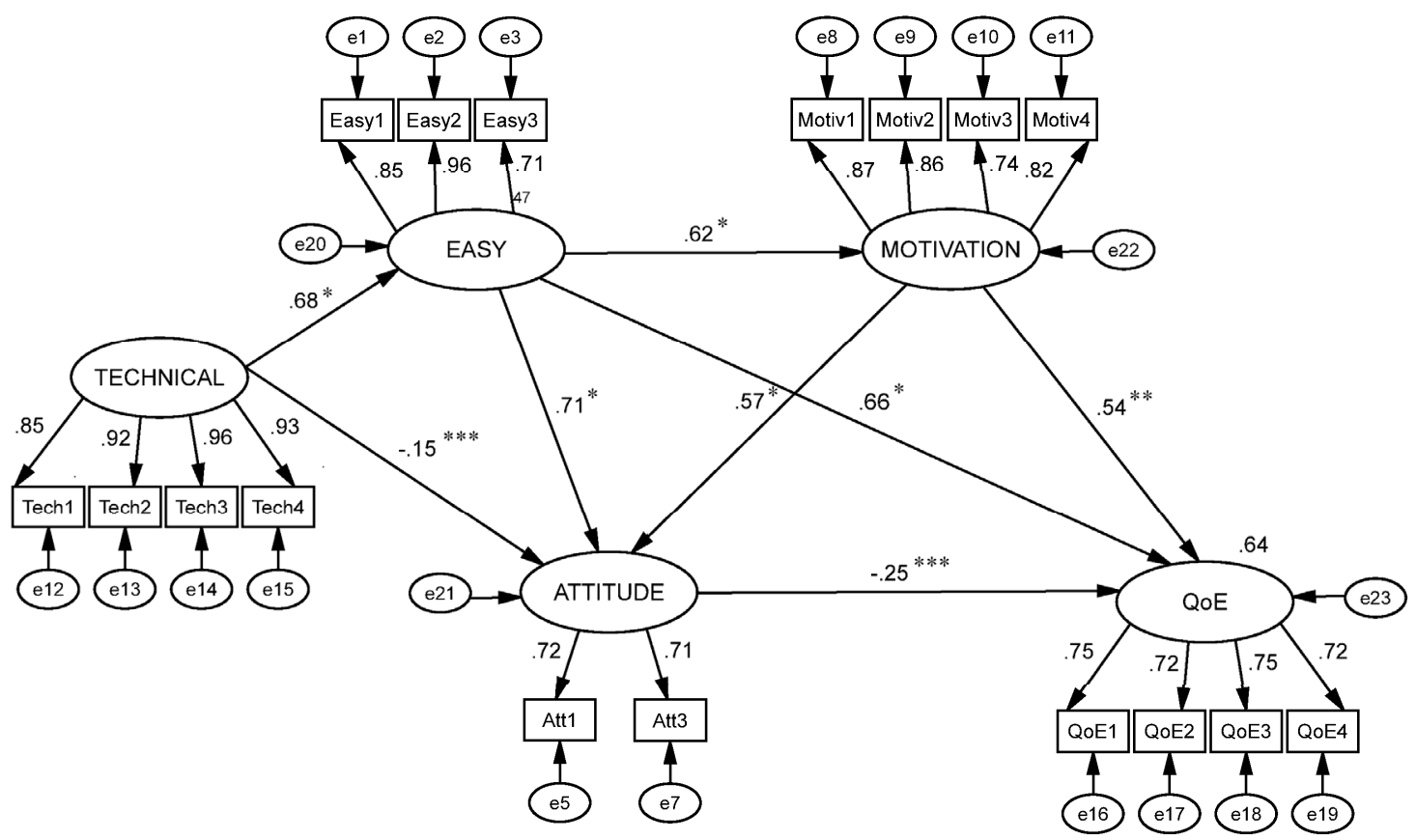

Figure 3: Results of the structural equation model during adult students' perceptions in a distance education learning environment based on a videoconferencing platform $\left({ }^{*} \mathbf{p}<0.001 ; * * \mathbf{p}<0.01 ; * * * p>0.05\right)$.

The structural equation model produced the following values for the necessary indicators:

- $\mathrm{CMIN}=357.278, \mathrm{df}=111, \mathrm{CMIN} / \mathrm{df}=3.219$ (according to Marsh and Hocevar (1985) a relative chi-square as low as 2 or as high as 5 indicated a reasonable fit);

- $\quad$ GFI $=0.914$ (goodness of fit index which should exceed 0.9 for a good model (Joreskog \& Sorbom, 1984));

- $\mathrm{CFI}=0.923$ (comparative fit index where, according to Hu and Bentler (1999), values > 0.9 indicate a very good fit);

- RMSEA $=0.05$ (root mean square error of approximation, where smaller values below 0.08 are preferable (Browne \& Cudeck, 1993)).

These values indicate proper model fit and alignment between the ultimate model (Figure 3) and collected data. The hypothesized model that included the path between TECHNICAL and QoE 
Malinovski, Vasileva-Stojanovska, Jovevski, Vasileva \& Trajkovik

(according to Hypothesis 2) produced values for GFI=0.834 and RMSEA=0.09, which are slightly below desired indicators, proving that the model correction was justified.

\section{Discussion}

The purpose of this study is to broaden our understanding of the nature of adult students while using videoconferencing for lifelong learning and predict or explain the determinants that influence their positive experiences during the learning process. The research results show that the QoE construct is significantly determined by EASY $(\beta=0.66, p<0.001)$ and MOTIVATION $(\beta=0.54, p=0.003)$ with a coefficient of determination $R^{2}$ of 0.64 . This indicates that the desired outcome variable for QoE can be strongly predicted when adult students participate in distance learning process based on an interactive videoconferencing platform. Therefore we can conclude that Hypotheses $5 a$ and $5 c$ are fully supported and reveal influencing factors that can be considered specific for adult students' QoE while engaging in similar distance educational activities. Even though it is inappropriate to generalize that the adult population is intimidated by the technological advancements or unwilling to participate in online learning (Donavant, 2009), the results have demonstrated that ease of participation and motivation to learn in similar environments are the main determinants for adult students' QoE. Additionally, if we follow Fidishun's (2000) assumptions and focus on factors that motivate adults and embrace them into the online environments through different educational methods, we can increase the level of adult students' positive experience. The findings have a number of implications for practice, especially for the stakeholders of the educational institutions that include videoconferencing-based learning environments for an adult population, which can help them to properly determine relevant factors that can improve the educational process.

Furthermore, indirectly, the factor loadings on EASY and MOTIVATION indicate to what extent their factors play a role in a higher level of positive students' QoE. For example, the high factor loading between EASY (unobserved variable) and Easy2 (observed variable) of 0.96 suggests that appropriateness and simplicity of teacher-student interaction predicts perceived QoE from the learning session. These finding complicate but do not contradict Schmidt and Moust's (1995) SEM analysis that emphasizes the importance of teacher-student communication and a positive learning atmosphere. Furthermore, the results show that adults prefer environments that closely resemble face-to-face education, since their orientation to learning shifts from content-oriented towards problem-centered learning (Knowles, 1980), which can be maximized through interactive discussions. In like manner, since Motiv1 and Motiv2 regressed higher on MOTIVATION as oppose to Motiv3, we can conclude that adults respond better to internal versus external motivators, which correlates with Knowles's (1980) theory of andragogy.

Path coefficients illustrating correlations between the other constructs, show strong connections between EASY and ATTITUDE $(\beta=0.71, p<0.001)$ and EASY and MOTIVATION $(\beta=0.62$, $\mathrm{p}<0.001)$ thus fully supporting Hypotheses $3 a$ and $3 b$, and a significant influence between TECHNICAL and EASY $(\beta=0.68, \mathrm{p}<0.001)$ thus supporting Hypothesis 1a. The system's performance and proper audio/video parameters showed a direct effect on students' ease of participation in the learning sessions and their interaction with the teacher. On the other hand, the easy usage influenced adults' motivation to use similar distance education systems and their general attitude and acceptance of these interactive technologies. Students' motivation also has a positive effect on general attitude and acceptance as reported with the path between MOTIVATION and ATTITUDE $(\beta=0.57, \mathrm{p}<0.001)$, thus fully supporting Hypothesis 4 . These findings correlate with Davis et al.'s (1989) TAM model, which states that perceived ease of use influences user attitudes, while explaining additional latent relationships that were presented in this study. The obtained results are very important since early identification of relevant variables could provide the 
means to increase the likelihood of positive students' experiences in similar learning environments.

Hypotheses $1 b$ and $5 b$ were rejected in this study, since we found no direct statistically significant effects between TECHNICAL and ATTITUDE ( $>>0.05)$ and ATTITUDE and QoE ( $>>0.05)$. Therefore, these results oppose the importance of attitude towards using technology in the technology acceptance model (Lee et al., 2005, Ngai, Poon, \& Chan, 2007; X. Wu \& Gao, 2011), since adult students' attitude towards the new technologies failed to predict their QoE.

Bearing in mind that we also rejected Hypothesis 2, this study has shown that adult students' QoE can be abstracted from the technological setup and system behavior, with a limitation for performance within acceptable levels (based on the technical observed variables). Since adults demonstrated intuitive understanding of content based on their personal experience and life histories (Jordan, Carlile, \& Stack, 2008), it is justifiable that variances in technical quality does not directly influence their QoE from the learning sessions.

\section{Conclusion}

The adult population engages in different lifelong learning activities through a variety of forms of learning experiences that include self-directed learning, lectures, conferences, seminars, workshops, etc. This type of students tends to be specific in their nature since they cover a wide age span, and have different life experiences and motivation for learning than traditional students involved in standard state educational programs for primary/secondary schools, universities, postgraduate studies, etc. Due to limitation of resources and possibilities, adult students can be considered as a target group that may directly benefit from the advantages of distance learning solutions.

This study researched adult students' QoE during distance learning activities in a form of interactive and collaborative training that utilize systems based on a videoconferencing platform. Even though distance education and technology are closely connected, we have tried to abstract the technological layer, focusing on social behavior and the cognitive level of this learning process. We have identified several variables, like ease of use and students' motivation, that can adequately explain and have the ability to predict the level of positive QoE. A structural equation model was proposed, tested, and validated while most of the causal relationships between the research constructs were well supported. The results showed that $64 \%$ of adult students' QoE in a distance education learning environment based on a videoconferencing platform was explained by the proposed model.

This quantitative QoE analysis helps adult readers interested in similar distance education activities to understand the social aspect and factors influencing their positive level of QoE from the learning process. At the same time, it provides relevant input for the stakeholders of distance education institutions to understand that students' experience is vitally important to the educational process and has to be considered as a relevant factor for their future development and proper positioning in the distance learning area.

In our future work, we will continue to use the proposed methodology while expanding the scope of work in different directions. We plan to evaluate adult distance learning virtual environments based on self-learning materials, prerecorded audio and video segments as a form of learnercontent interactions, as well evaluate different collaborative solutions as a learner-learner interaction. We will use the model presented in this study and conduct further analyses while trying to predict students' QoE in these environments. Based on the results reported in this study, we will focus on the development of a neuro-fuzzy model that can be used to identify Quality of Learning (QoL) as a causal relationship between different input parameters like objective factors, learning capabilities, previous knowledge, a clear set of learning goals etc., including QoE. 


\section{References}

Ajzen, I., \& Fishbein, M. (1980). Understanding attitudes and predicting social behavior. Englewood Cliffs, NJ: Prentice-Hall.

Bollen, K. A. (1989). Structural equations with latent variables. New York: John Wiley and Sons, Ltd.

Bower, B. L., \& Hardy, K. P. (2004). From correspondence to cyberspace: Changes and challenges in distance education. New Directions for Community Colleges, 2004(128), 5-12.

Brady, K. P., Holcomb, L. B., \& Smith, B. V. (2010). The use of alternative social networking sites in higher educational settings: A case study of the e-learning benefits of Ning in education. Journal of Interactive Online Learning, 9(2), 151-170.

Bouhnik, D., \& Carmi, G. (2012). E-learning environments in academy: Technology, pedagogy and thinking dispositions. Journal of Information Technology Education: Research, 11(1), 201-219.

Browne, M. W., \& Cudeck, R. (1993). Alternative ways of assessing model fit. In K. A. Bollen \& J. S. Long (Eds.), Testing structural equation models (pp. 136-162). Sage Publications: Newbury Park, CA.

Byrne, B. M. (2001). Structural equation modeling with AMOS, EQS, and LISREL: Comparative approaches to testing for the factorial validity of a measuring instrument. International Journal of Testing, 1(1), 55-86.

Cercone, K. (2008). Characteristics of adult learners with implications for online learning design, $A A C E$ Journal, 16(2), 137-159.

Churchill Jr, G. A. (1979). A paradigm for developing better measures of marketing constructs. Journal of Marketing Research, 64-73.

Curran, P. J., West, S. G., \& Finch, J. F. (1996). The robustness of test statistics to nonnormality and specification error in confirmatory factor analysis. Psychological Methods, 1(1), 16-29

Davis, F. D., Bagozzi, R. P., \& Warshaw, P. R. (1989). User acceptance of computer technology: A comparison of two theoretical models. Management Science, 35(8), 982-1003.

Donavant, B. W. (2009). The new, modern practice of adult education online instruction in a continuing professional education setting. Adult Education Quarterly, 59(3), 227-245.

Eastmond, D. V. (1998). Adult learners and Internet-based distance education. New directions for adult and continuing education, Summer(78), 33-41.

Eyitayo, O. (2013). Using adult learning principles as a framework for learning ICT skills needed for research projects. Journal of Information Technology Education: Innovations in Practice, 12(1), 73-89. Retrieved from http://www.jite.org/documents/Vol12/JITEv12IIPp073-089Eyitayo1163.pdf

Garrison, D. R. (2011). E-learning in the 21st century: A framework for research and practice. London: Taylor \& Francis.

Giancola, J. K., Grawitch, M. J., \& Borchert, D. (2009). Dealing with the stress of college a model for adult students. Adult Education Quarterly, 59(3), 246-263.

Gill, D., Parker, C., \& Richardson, J. (2005). Twelve tips for teaching using videoconferencing. Medical Teacher, 27(7), 573-577.

Gong, Y., Yang, F., Huang, L., \& Su, S. (2009). Model-based approach to measuring quality of experience. In Emerging Network Intelligence, 2009 First International Conference on (pp. 29-32). IEEE.

Hair, J. F., Anderson, R. E., Tatham, R. L., \& Black, W. C. (1998). Multivariate data analysis (5 ${ }^{\text {th }}$ ed.). NY: Prentice Hall International.

Hannafin, M. J., Hill, J. R., Land, S. M., \& Lee, E. (2014). Student-centered, open learning environments: Research, theory, and practice. In Handbook of research on educational communications and technology (pp. 641-651). New York: Springer.

Hrastinski, S. (2008). Asynchronous and synchronous e-learning. Educause Quarterly, 31(4), 51-55. 
Hu, L. T., \& Bentler, P. M. (1999). Cutoff criteria for fit indexes in covariance structure analysis: Conventional criteria versus new alternatives. Structural Equation Modeling: A Multidisciplinary Journal, $6(1), 1-55$.

Fidishun, D. (2000, April). Andragogy and technology: Integrating adult learning theory as we teach with technology. Proceedings of the 2000 Mid-South Instructional Technology Conference. Murfreesboro, TN: Middle Tennessee State University.

Field, J. (2006). Lifelong learning and the new educational order. Stoke-on-Trent, UK: Trentham Books.

Jarvis, P. (1995). Adult and continuing education: Theory and practice. London: Routledge.

Jordan, A., Carlile, O., \& Stack, A. (2008). Approaches to learning: A guide for educators. Berkshire, UK: McGraw-Hill International.

Joreskog, K. G., \& Sorbom, D. (1984). LISREL VI user's guide. Mooresville, IN: Scientific Software.

Kalliris, G., Dimoulas, C. A., Veglis, A., \& Matsiola, M. (2011). Investigating Quality of Experience and Learning (QoE \& QoL) of audiovisual content broadcasting to learners over IP networks. Computers and Communications (ISCC), 2011 IEEE Symposium on (pp. 836-841). IEEE.

Kist, A. A., \& Brodie, L. (2012). Quality of service, quality of experience and online learning. Proceedings of the Frontiers in Education Conference (pp. 1-6), Seattle, Washington.

Knowles, M. S. (1980). The modern practice of adult education: From pedagogy to andragogy. New York: Cambridge Books.

Knowles, M. S., Holton, E. F., \& Swanson, R. A. (1998). The adult learner: The definitive classic in adult education and human resource development. Houston, TX: Gulf Publishing.

Kolb, D. A. (1984). Experiential learning: Experience as the source of learning and development. Englewood Cliffs, NJ: Prentice-Hall

Lawson, T., Comber, C., Gage, J., \& Cullum-Hanshaw, A. (2010). Images of the future for education? Videoconferencing: A literature review. Technology, Pedagogy and Education, 19(3), 295-314.

Lee, M. K., Cheung, C. M., \& Chen, Z. (2005). Acceptance of Internet-based learning medium: The role of extrinsic and intrinsic motivation. Information \& management, 42(8), 1095-1104.

LeNoue, M., Hall, T., \& Eighmy, M. A. (2011). Adult education and the social media revolution. Adult Learning, 22(2), 4-12.

Levenberg, A., \& Caspi, A. (2010). Comparing perceived formal and informal learning in face-to-face versus online environments. Interdisciplinary Journal of E-Learning and Learning Objects, 6(1), 323333. Retrieved from http://www.ijello.org/Volume6/IJELLOv6p323-333Levenberg706.pdf

Liu, I. F., Chen, M. C., Sun, Y. S., Wible, D., \& Kuo, C. H. (2010). Extending the TAM model to explore the factors that affect Intention to Use an Online Learning Community. Computers \& Education, $54(2), 600-610$.

Longworth, N. (2013). Lifelong learning in action: Transforming education in the 21st century. London: Routledge.

Malinovski, T., Lazarova, M., \& Trajkovik, V. (2012). Learner-content interaction in distance learning models: Students' experience while using learning management systems. International Journal of Innovation in Education, 1(4), 362-376.

Mason, R. (2006). Learning technologies for adult continuing education. Studies in Continuing Education, $28(2), 121-133$.

Marsh, H. W., \& Hocevar, D. (1985). Application of confirmatory factor analysis to the study of selfconcept: First-and higher-order factor models and their invariance across groups. Psychological Bulletin, 97(3), 562-582. 
Milheim, K. L. (2007). Influence of technology on informal learning. Adult Basic Education and Literacy Journal, 1(1), 21-26.

Merriam, S. B., \& Caffarella, R. S. (1991). Learning in adulthood. A comprehensive guide. San Francisco: Jossey-Bass.

Molnar, A., Hava-Muntean, C. \& Cristea, A. (2009). Reusable quality of experience aware adaptation strategies for authoring adaptive e-learning. In T. Bastiaens et al. (Eds.). Proceedings of World Conference on E-Learning in Corporate, Government, Healthcare, and Higher Education 2009 (pp. 3801-3810). Chesapeake, VA: AACE.

Moore, M. G. (1997). Theory of transactional distance. In D. Keegan (Ed.). Theoretical principles of distance education (pp. 22-38), New York: Routledge.

Moore, M. G., \& Kearsley, G. (1996). Distance education: A systems view. Belmont, CA: Wadsworth.

Murphy, E., Rodríguez-Manzanares, M. A., \& Barbour, M. (2011). Asynchronous and synchronous online teaching: Perspectives of Canadian high school distance education teachers. British Journal of Educational Technology, 42(4), 583-591.

Ng, E. M. W., Shroff, R. H., \& Lim, C.P. (2013). Applying a modified technology acceptance model to qualitatively analyse the factors affecting e-portfolio implementation for student teachers' in field experience placements. Issues in Informing Science and Information Technology, 10, 355-365. Retrieved from http://iisit.org/Vol10/IISITv10p355-365Ng0115.pdf

Ngai, E. W., Poon, J. K. L., \& Chan, Y. H. C. (2007). Empirical examination of the adoption of WebCT using TAM. Computers \& Education, 48(2), 250-267.

Nunnally, J. C. (1978). Psychometric theory (2nd Ed.). New York: McGraw-Hill.

Quality of Experience. In Wikipedia, The Free Encyclopedia. Retrieved February 10, 2011, from http://en.wikipedia.org/wiki/Quality of experience

Richardson, J. T. (2013). Approaches to studying across the adult life span: Evidence from distance education. Learning and Individual Differences, 26, 74-80.

Saadé, R., Nebebe, F., \& Tan, W. (2007). Viability of the "technology acceptance model" in multimedia learning environments: a comparative study. Interdisciplinary Journal of E-Learning and Learning Objects, 3(1), 175-184. Retrieved from http://www.ijello.org/Volume3/IJKLOv3p175184Saade393.pdf

Sahin, I., \& Shelley, M. (2008). Considering students' perceptions: The Distance Education Student Satisfaction Model. Educational Technology \& Society, 11(3), 216-223.

Schmidt, H. G., \& Moust, J. H. (1995). What makes a tutor effective? A structural-equations modeling approach to learning in problem-based curricula. Academic Medicine, 70(8), 708-14.

Selwyn, N., Gorard, S., \& Furlong, J. (2005). Adult learning in the digital age: Information technology and the learning society. London: Routledge.

Smith, R. O. (2005). Working with difference in online collaborative groups. Adult Education Quarterly, 55(3), 182-199.

Somenarain, L., Akkaraju, S., \& Gharbaran, R. (2010). Student perceptions and learning outcomes in asynchronous and synchronous online learning environments in a biology course. MERLOT Journal of Online Learning and Teaching, 6, 353-356.

Stone, E. W. (1986). The growth of continuing education. Library Trends, 34(3), 489-513.

Taylor, T. (2009). Video conferencing: An effective solution to long distance student placement support? Widening Participation and Lifelong Learning, 11(3), 44-48.

Tight, M. (2002). Key concepts in adult education and training. London: Routledge. 
Trigwell, K., \& Prosser, M. (1991). Improving the quality of student learning: the influence of learning context and student approaches to learning on learning outcomes. Higher education, 22(3), 251-266.

Weimer, M. (2013). Learner-centered teaching: Five key changes to practice. San Francisco, CA: John Wiley \& Sons.

Wang, J., \& Staver, J. R. (2001). Examining relationships between factors of science education and student career aspiration. The Journal of Educational Research, 94, 312-319.

Wang, Y., \& Chen, N. S. (2007). Online synchronous language learning: SLMS over the Internet. Innovate, $3(3), 1-7$.

Wu, X., \& Gao, Y. (2011). Applying the extended technology acceptance model to the use of clickers in student learning: Some evidence from macroeconomics classes. American Journal of Business Education (AJBE), 4(7), 43-50.

Wu, W., Arefin, A., Rivas, R., Nahrstedt, K., Sheppard, R., \& Yang, Z. (2009). Quality of experience in distributed interactive multimedia environments: Toward a theoretical framework. Proceedings of the 17th ACM International Conference on Multimedia (pp. 481-490), New York, NY, USA.

Yamagata-Lynch, L. C. (2014). Blending online asynchronous and synchronous learning. The International Review of Research in Open and Distance Learning, 15(2).

Zhang, D., Xu, Y., \& Cheng, C. (2011). A QoE assessment system in distance education. Engineering, $3(1), 90$.

\section{Biographies}

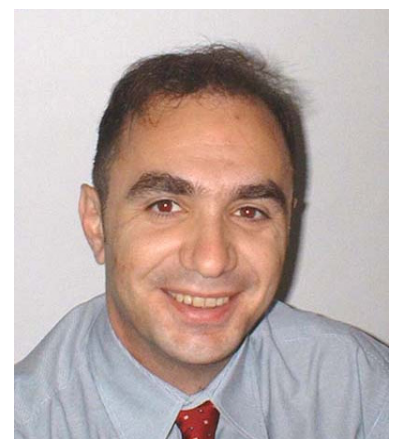

Toni Malinovski completed his Master Degree in Computer Science at the Faculty of Electrical Engineering and Information Technologies, Ss. Cyril and Methodius University - Skopje, Macedonia in 1998. His major research interests include distance education, rich communication media, QoS, QoE, videoconferencing and distributed systems. Works at National Bank of the Republic of Macedonia and holds the position as IT senior advisor. He is author and co-author of several papers published in international journals, international and national conferences.

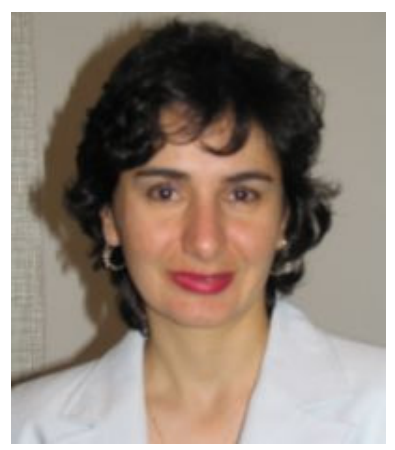

Tatjana Vasileva-Stojanovska has graduated at the Faculty of Natural Sciences in 1994. She received her Master Degree from the Faculty of Electrical Engineering and Information Technology in 2000. Her research interests are focused in distance education, intelligent agents, neuro-fuzzy systems and fuzzy logic control systems. She works at the National Bank of the Republic of Macedonia holding the position of senior programmer. 


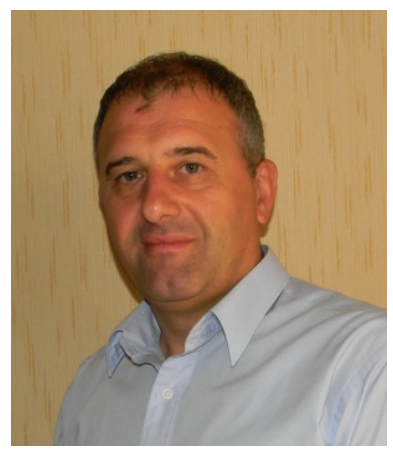

Dobri Jovevski graduated in 2000 at the Faculty of Education "St. Kliment Ohridski" Skopje in the St. Cyril and Methodius, University of Skopje, Macedonia, as a teacher for an elementary school. He is employed as a school teacher in Primary school "Ilinden", Kriva Palanka, Macedonia. The most important part of his professional work is placed on innovative and creative teaching the students to become a natural learning process, and students effectively and efficiently master the skills of the 21st century. As an associate he has participated in making several digital contents for students in early classes.

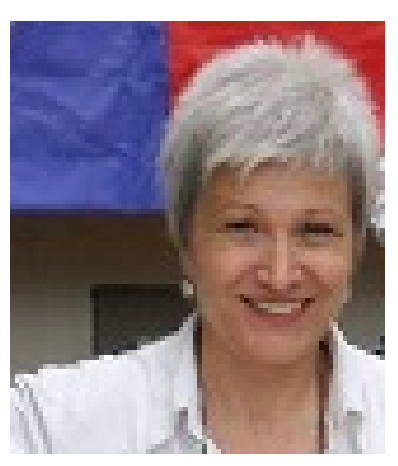

Marina Vasileva completed her Master Degree at the Pedagogical Faculty, Ss. Cyril and Methodius University - Skopje, Macedonia in 2011. She is a PhD candidate at the Faculty of Computer Science and Engineering at the Ss. Cyril and Methodius University - Skopje, Macedonia, with research activities that focus on didactic aspects for the development of educational contents which utilize ICT. Works at Primary School "Ss. Cyril and Methodius" in Skopje and also holds the position as IT teacher for students at the Ss. Cyril and Methodius University - Skopje, Macedonia.

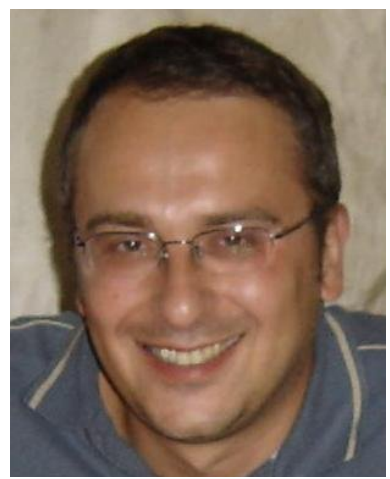

Vladimir Trajkovik received his $\mathrm{PhD}$ Degree at the Ss. Cyril and Methodius University - Skopje, Macedonia in 2003. Currently he is a Professor at the Faculty of Computer Science and Engineering at the same university. His research interests include: information systems analyses and design, distributed computer systems, distance educational systems, multi-agent systems, ICT-based collaboration systems and mobile services. He has over 100 publications in various international conferences and international journals. 